\title{
A Study of the Size and Shape of Cross Sections of Hair from Four Races of Men'
}

\author{
DONAIJD G. VERNALL
}

Department of Anatomy, The University of Michigan, Ann Arbor, Michigan

The physical characters of hair have often been given a leading position among the attributes used for the classification of human races. Many of the descriptions of hair features used in the past, however, have been lacking in precision. Only recently have investigators begun to apply more precise measures to human hair characters.

The variability which occurs among the hairs from a single person, and among persons known to belong to the same race, however, presents a serious obstacle to the use for racial classification of even precisely measured characters. Considerable uncertainty exists about the amount of variability among the hairs of a single person as compared to the variability among persons, and about the variability among persons within a racial group as compared to the variability among racial groups.

This study supports and extends previous studies of hair types of human races. It applies a set of measures to the treatment of variation in hair characters; and submits these measures to an analysis of variance to determine the amount of variation within and among races.

\section{METHODS}

\section{Collection of sample}

Hair samples were collected from 86 males who were 20 to 30 years old as follows: 20 Chinese who had been born on the Chinese mainland; 21 individuals who had been born, or whose parents had been born, in Great Britain, Germany, France, or Holland; 26 Asiatic Indians who were born in India; and 19 Negroids of whom 9 were born in Nigeria, 9 in the United States, and one in Jamaica.

In no case was any individual excluded from the sample on the basis of hair char- acter, although no individual was included who acknowledged mixed ancestry.

Each hair sample was cut as close to the scalp as possible from the area overlying the external occipital protuberance.

\section{Preparation of specimens}

Hair samples were cleaned by soaking for 24 hours in each of 5 changes of 100 $\mathrm{ml}$ of carbon tetrachloride. The samples were blotted with paper towels and airdried for several minutes after each immersion before being placed in the next jar of cleaning solution.

Parlodion was used to embed the hairs in preparation for sectioning. The sections, cut with the Hardy sectioning device (Steggerda, '40) and a Gillette microtome blade, were mounted on a slide with thin piccolyte. A glass coverslip of " $O$ " thickness was applied, and subjected to light pressure to flatten the curled film of Parlodion. The slide was placed in a drying oven for a week.

\section{Measurements}

A research microscope equipped with a $2 \mathrm{~mm}$ N.A. 1.30 apochromatic objective and $15 \times$ compensating eyepiece was used to measure the mounted cross section of hairs under a magnification of $1350 \times$. The Köhler method (Shillaber, '44; 93-96) of illuminating the field was used. A micrometer disc served to measure the lengths of the hair axes to the nearest half quadrat of the micrometer disc. Each quadrat measured 8.2 microns $(\mu)$ on each side.

Measurements were made on a single cross section of each hair, about $0.5 \mathrm{~cm}$ from the proximal end. The first 30 cross

\footnotetext{
1 This paper represents a condensation of a section of a dissertation submitted in partial fulfillment of the requirements for the degree of Doctor of Philosophy in The University of Michigan.
} 
sections of hair encountered in each mounted specimen were measured to avoid any bias in the selection of hairs. Preliminary statistical analysis indicated that a sample of this size would be adequate to measure the variability.

The shape of hair in cross section is elliptical and varies from a nearly circular ellipse with major and minor axes approximately equal in length to a more flattened type with the major axis twice the length of the minor axis. Rare modifications impart a kidney, pear or triangular shape. An index, the quotient obtained by dividing the length of the minor axis by the length of the major, is used as a measure of shape. The area of a hair cross section is calculated from major and minor axes by assuming that the shape of all hairs approaches that of an ellipse, and by using the formula ( $p i D_{1} D_{2} / 4$ ) for the area of an ellipse.

\section{RESULTS}

The measurements of each character indicate that much variability occurs among the hairs from each person, among the persons within each race, and among races (table 1 ). The measurements have accordingly been subjected to an analysis of variance (Snedecor, '46: 214-226) which reveals that the variability among persons in each race is significantly greater than the within-person variability among hairs (table 2).

Further analysis indicates that, for each of the 4 traits measured, the variability among the 4 races, here considered, is significantly greater than the variability among the persons within each race (table 2).

In an effort to determine which races differ significantly from the other races, each group was compared separately with

TABLE 1

Racial means and their standard errors of length of major axis, length of minor axis, area and index of hair cross sections

\begin{tabular}{lcccc}
\hline & Major axis & Minor axis & Area & $\begin{array}{c}\text { Index } \\
\frac{\text { minor axis }}{\text { major axis }}\end{array}$ \\
\hline Chinese & $\mu$ & $\mu$ & $\mu^{2}$ & \\
Western Europeans & $94.28 \pm 3.05$ & $76.79 \pm 2.12$ & $\mathbf{5 8 1 6 . 9 \pm 4 0 7 . 2}$ & $0.8264 \pm 0.0117$ \\
Asiatic Indians & $\mathbf{8 1 . 9 4 \pm 2 . 4 7}$ & $56.74 \pm 1.33$ & $3786.5 \pm 185.9$ & $0.7116 \pm 0.0141$ \\
Negroids & $92.94 \pm 1.93$ & $66.49 \pm 1.54$ & $4993.5 \pm 202.6$ & $0.7292 \pm 0.0112$ \\
& $98.23 \pm 2.45$ & $58.52 \pm 1.87$ & $4648.9 \pm 255.8$ & $0.5996 \pm 0.0107$ \\
\hline
\end{tabular}

TABLE 2

Results of analysis of variance of the measurements of hair sections

\begin{tabular}{|c|c|c|c|c|c|c|c|}
\hline \multirow{3}{*}{ Tests } & \multirow{3}{*}{$\begin{array}{c}\text { Degtees of } \\
\text { freedom }\end{array}$} & \multirow{2}{*}{\multicolumn{2}{|c|}{$\begin{array}{l}F \text { values } \\
\text { required for } \\
\text { significance } \\
\text { levels of: }\end{array}$}} & \multicolumn{4}{|c|}{ F values obtained } \\
\hline & & & & \multirow{2}{*}{$\begin{array}{l}\text { Length } \\
\text { of } \\
\text { major } \\
\text { axis }\end{array}$} & \multirow{2}{*}{$\begin{array}{l}\text { Length } \\
\text { of } \\
\text { minor } \\
\text { axis }\end{array}$} & \multirow{2}{*}{ Area } & \multirow{2}{*}{ Index } \\
\hline & & 0.05 & 0.01 & & & & \\
\hline \multicolumn{8}{|l|}{ Within races: } \\
\hline Chinese & $19 / 580$ & 1.61 & 1.94 & $18.95^{2}$ & $19.51^{2}$ & $30.80^{2}$ & $10.31^{2}$ \\
\hline Western Europeans & $20 / 609$ & 1.59 & 1.91 & $12.45^{2}$ & $11.26^{2}$ & $13.47^{2}$ & $12.05^{2}$ \\
\hline Asiatic Indians & $25 / 754$ & 1.52 & 1.80 & $9.45^{2}$ & $16.72^{2}$ & $14.86^{2}$ & $8.70^{2}$ \\
\hline Negroids & $18 / 551$ & 1.63 & 1.97 & $13.64^{2}$ & $19.44^{2}$ & $23.14^{2}$ & $8.38^{2}$ \\
\hline Among all 4 races & $3 / 82$ & 2.72 & 4.03 & $7.77^{2}$ & $26.93^{2}$ & $9.45^{2}$ & $53.37^{2}$ \\
\hline \multicolumn{8}{|l|}{ Between races } \\
\hline Chinese-W. Eur. & $1 / 39$ & 4.09 & 7.33 & $10.10^{2}$ & $65.87^{2}$ & $28.10^{2}$ & $21.07^{2}$ \\
\hline Chinese-As. Ind. & $1 / 44$ & 4.06 & 7.24 & 0.02 & $60.43^{2}$ & 3.76 & $35.22^{2}$ \\
\hline Chinese-Negroids & $1 / 37$ & 4.10 & 7.37 & 1.01 & $41.52^{2}$ & $6.07^{1}$ & $202.15^{2}$ \\
\hline W. Eur.-As. Ind. & $1 / 45$ & 4.06 & 7.22 & $12.87^{2}$ & $21.99^{2}$ & $18.64^{2}$ & 0.97 \\
\hline W. Eur.-Negroids & $1 / 38$ & 4.10 & 7.35 & $22.10^{2}$ & 0.62 & $7.71^{2}$ & $37.72^{2}$ \\
\hline As. Ind.-Negroids & $1 / 43$ & 4.06 & 7.26 & 2.95 & $54.00^{2}$ & 1.14 & $65.76^{2}$ \\
\hline
\end{tabular}

${ }^{1}$ Shows significance in the $0.05-0.01$ probability range.

2 Shows significance beyond the 0.01 probability range. 
each of the other groups in regard to the various traits.

\section{Length of major axis}

The mean length of major axis for the hairs from any one person ranges from $58.49 \pm 2.46 \mu$ for a Western European to $125.00 \pm 4.30$ for a Chinese. The variances of the length of the major axes of the hair sections from each person range from 52.092 for a Negro to 726.520 for an Asiatic Indian.

So far as length of major axis is concerned, Negroid hairs are on the average the largest; Western European, the smallest; while Chinese and Asiatic Indian hairs are intermediate in size (table 1). The difference between Western Europeans and each of the three other groups is significant, although these other groups do not differ significantly from each other in this respect.

\section{Length of minor axis}

The mean length of minor axis for the 30 hairs from any one person ranges from $43.05 \pm 1.16 \mu$ for a Western European to $100.18 \pm 2.99$ for a Chinese. The range of the within-person variances from 25.428 for a Negroid individual to 313.478 for an Asiatic Indian indicates further the variability among individuals for this trait.

If length of minor axis is used as the criterion, the Chinese have on the average the largest hairs and Western Europeans the smallest (table 1). Asiatic Indians are in general intermediate between these two extremes. The Western European and Negroid subjects are similar to each other and are the only pair which do not differ significantly in regard to length of minor axis.

\section{Cross-sectional area}

The person whose hairs have the smallest mean cross-sectional area is a Western European with a mean of $2017.4 \pm 122.7$ $\mu^{2}$. The hair sections with the largest mean area are from a Chinese and measure $10105.2 \pm 535.0 \mu^{2}$. The within-person variances for area of hair sections range from 362,163 for a Negro to $8,585,186.5$ for a Chinese.

Hairs from Chinese have the greatest mean area (table 1); those from Western
Europeans, the smallest. The cross-sectional areas of Asiatic Indian and Negroid hairs are similar to each other, but intermediate between those of the Chinese and Western European hairs. The differences between the Western Europeans and the other three groups are significant. The Negroid subjects differ from the Chinese at the 0.05 level of significance. The Asiatic Indian sample, however, does not differ significantly from the Chinese nor from the Negroid samples.

\section{Index of hair cross sections}

The hair index provides another measure of the combined effect of the major and minor axes and is used as a reflection of the shape of the cross section of the hair.

The smallest index measured in this study is 0.50 which is the index of a hair with the shape of a flattened ellipse and with a major axis twice as great as the minor axis. The largest index measured is 1.00. In such hairs the shape of the cross sections closely approximates that of a circle. This range is in agreement with those reported by Danforth ('25) and Kneberg ('35).

The smallest mean obtained from the indices of the hairs from any single person, a Negroid subject, is $0.5370 \pm 0.0078$, and the largest within-person mean index is $0.9146 \pm 0.0129$ for a Chinese. The within-person variances for the index range from 0.0018 to 0.0221 . Both of these individuals belong to the Negroid group.

As measured by the index (table 1), the Chinese hair sections are the most nearly circular in shape; the Negroid sections are the most flattened; and the Western European and Asiatic Indian hair sections are intermediate in shape. The latter two groups do not differ significantly from each other, but all other differences between races in regard to hair index are statistically significant.

\section{DISCUSSION}

The methods for obtaining, sectioning, and measuring the hairs were designed to secure samples suitable for statistical treatment. Sampling was restricted to subjects between the ages of 20 and 30 years in order to minimize the effect of age on hair 
character (Trotter, '30; Duggins and Trotter, '51). Between these ages, the amount of variation in hair character due to age is slight (Trotter and Duggins, '48). The possible variability in hair characters due to the difference in the sex of the subjects (Trotter and Dawson, '34; Steggerda and Seibert, '41) was avoided by measuring hair specimens from males only. Measurements were made on a single cross section taken from approximately the same area of each hair in an effort to minimize the variation that occurs in each hair throughout its length from base to tip (Kneberg, '35; Garn, '46).

The Chinese, Asiatic Indian, Western European, and Negroid individuals who supplied the hair samples for this study may not be a random sample of their respective populations, as most of the subjects were university students. Consequently, the racial differences here observed cannot be extended to the whole populations of these 4 races. Nevertheless, bias was avoided so far as possible in taking the hair samples and it is believed that they do represent adequately the individual and the series of individuals measured. Consequently, it is believed that the differences between the races shown by these measurements indicate the type of racial differences in hair characters which actually occur.

\section{Chinese}

Although the Chinese rank second in regard to length of major axis, they have on the average the largest hairs of the 4 groups in terms of Iength of minor axis and area of cross section. They differ significantly only from the Western Europeans so far as length of major axis is concerned, while in terms of length of minor axis they differ significantly from each of the other groups. In terms of cross-sectional area, they are, again, significantly different from Western Europeans, but differ from $\mathrm{Ne}$ groids at only the 0.05 level and from Asiatic Indians not at all.

The shape of the cross sections of hairs of the Chinese is more nearly circular on the average than that of any of the other races. The mean index for the Chinese is $0.8264 \pm 0.0117$ and is significantly differ- ent from that for any other race. Woodbury and Woodbury ('32) obtained indices for North American Indian tribes that, although smaller than that obtained here for the Chinese, are larger than those obtained in the present study for the Western European, Asiatic Indian, or Negroid groups.

\section{Western European}

The Western Europeans have on the average the smallest hairs in cross section of the 4 races here considered (table 1 ). This holds true for length of major axis, length of minor axis, and, concomitantly, the area. The differences are significant in all cases but one, namely the difference in length of minor axes between Western European and Negroid samples.

The shape of the cross section of hair from Western Europeans is on the average like that of hair from Asiatic Indians, and intermediate between that of Chinese hair and that of Negroid hair. The Western Europeans do not differ significantly from the Asiatic Indians but are significantly different from each of the others at the 0.01 level of significance.

\section{Asiatic Indians}

The cross sections of hairs from Asiatic Indians are generally intermediate in size relative to the other groups. They are significantly larger than those of Western Europeans in all three measures of size. They exceed the cross sections of Negroid hairs in length of minor axis (difference significant at the 0.01 level) and in area (difference not significant) but are surpassed by those of Negroid hairs in length of major axis (difference significant at the 0.01 level). Cross sections of hair from Asiatic Indians are out-ranked by those from Chinese in regard to all three measures of size, although, except for differences in length of minor axis, these differences are not significant.

Basu ('41) in a study of 50 adult male Noluas of Bengal reported a mean crosssectional surface of $0.00315 \mathrm{~mm}^{2}$ which differs considerably from the mean area obtained in this study, $0.0049 \mathrm{~mm}^{2}$. Such a difference, however, might be anticipated since Basu's Noluas are a small isolated subsample of the Asiatic Indians as a whole. 
The shape of the cross sections of hair from Asiatic Indians does not differ significantly from that of Western Europeans (table 2). Both of these groups have hair which is intermediate in shape of cross section between those of the Chinese and Negroid groups, and these differences are significant. Basu ('41) obtained a mean index of 0.774 for hair samples from the Bengalese Noluas, a value intermediate between the mean index, $0.7292 \pm 0.0112$, obtained here for the Asiatic Indians, and $0.8263 \pm 0.0117$, the mean index obtained here for the Chinese.

\section{Negroids}

The cross sections of hairs from Negroid subjects have the longest major axes, on the average, of all the groups here considered, although they differ significantly only from Western European hair cross sections in regard to this characteristic. When the other measures of size are considered, it is found that the Negroid sample is outranked by the Chinese and Asiatic Indian groups but exceeds the Western European. Most of these differences are significant (table 2).

The elliptical shape of the cross sections of Negroid hairs is in general the most flattened of those of the 4 races, and consequently the average index for the Negroid sample is the smallest. Furthermore, the differences between the Negroid group and each of the other racial groups are significant at the 0.01 level, so that shape of cross section is apparently a more useful criterion for distinguishing Negroid hairs than is any single measurement of size. These results are in agreement with those reported by Steggerda and Seibert in '41.

\section{SUMMARY}

Measurements were made of cross sections of 30 hairs collected from the occipital region from each of 86 males, 20 to 30 years of age. Of this group, 19 are Negroid; 26 are Asiatic Indian; 21 are Western European; and 20 are Chinese.

Among the hairs from each person, variability is high for all the characters measured: length of the major and minor axes of the cross section, cross-sectional area, and cross-sectional shape.
Among those persons of each racial type, variability also is high for all of these measures. Highly significant $F$ values were obtained from an analysis of the amongperson and within-person variability within each of the 4 racial groups.

Among the races included in the study, variability, for each of the traits measured, is significantly greater than the variability among persons within each race. Racial differences consequently do exist within this sample for each attribute.

Chinese have, in general, the largest and most nearly round hairs of the 4 races measured in this study.

The Western Europeans included in this study have, on the average, the smallest hairs in cross section of the 4 groups.

The Asiatic Indian hair sections examined in this study are indistinguishable in shape from those of the Western Europeans. Both are intermediate between the most nearly circular Chinese hair sections and the Negroid hair sections, which were most flattened in shape. In size of cross section, hairs of Asiatic Indians were exceeded by those of the Chinese in all respects and by Negroid hairs so far as length of major axis is concerned.

The flattened elliptical shape of the $\mathrm{Ne}$ groid hair sections is their most characteristic feature. In mean length of major axis, they are not significantly different from the Chinese nor from the Asiatic Indians. In the mean length of the minor axis, they are not significantly different from the Western Europeans. In mean area, they are not significantly different from the Asiatic Indians.

It is believed that the differences between the races shown by these measurements indicate the type of racial differences which actually occur in hair characters.

\section{LITERATURE CITED}

Basu, M. N. 1941 Study of the head-hair of the Noluas of Bengal. Univ. Calcutta Anthrop. Papers, 6: 79-80.

Danforth, C. H. 1925 The hair. Nat. History, 26: 1 .

Duggins, O. H., and M. Trotter 1951 Changes in morphology of hair during childhood. Ann. N. Y. Acad. Sci., 15: 569-575.

Garn, S. M. 1946 Hair structure related to hair form. Amer. Journ. Phys. Anthrop., 4: 252, abs. no. 2. 
Kneberg, M. 1935 Improved technique for hair examination. Ibid., 20: 51-67.

Shillaber, C. P. 1944 Photomicrography in Theory and Practice. New York: John Wiley and Sons.

Snedecor, G. W. 1946 Statistical Methods Applied to Experiments in Agriculture and Biology, 4th ed. Ames: Iowa State College Press.

Steggerda, M. 1940 Cross sections of human hair from four racial groups. Journ. Hered., 31: $474-476$.

Steggerda, M., and H. C. Seibert 1941 Size and shape of head hair from six racial groups. Ibid., 32: 315-318.
Trotter, M. 1930 The form, size, and color of head hair in American whites. Amer. Journ. Phys. Anthrop., 14: 433-445.

Trotter, M., and H. Dawson 1934 The hair of French Canadians. Ibid,, 18: 443-456.

Trotter, M., and O. H. Duggins 1948 Age changes in head hair from birth to maturity. I. Index and size of hair of children. Ibid., n.s. 6: 489-506.

Woodbury, G., and E. T. Woodbury 1932 Differences between Certain of the North American Indian Tribes as Shown by a Microscopical Study of Their Head Hair. Publ. State Hist. Soc. Colorado, $37 \mathrm{pp}$. 